\title{
Study on the Factor Influencing Smoking Cessation Among Adolescent Smokers
}

\section{흡연경험 청소년의 현재 금연에 영향을 미치는 요인}

\author{
Young-Ju Jee ${ }^{1}$, Yoon-Ji Kim² \\ 지영주 1 , 김윤지 ${ }^{2}$ \\ ${ }^{1}$ Associate Professor, Department of Nursing, Kyungnam University, Korea, \\ jeeyoungju@kyungnam.ac.kr \\ ${ }^{2}$ Associate Professor, Department of Nursing, Dong-Eui Institute of Technology, Korea, \\ yoonji@dit.ac.kr
}

Corresponding author: Yoon-Ji Kim

\begin{abstract}
The purpose of this study was to identify factors affecting attempts to quit smoking among adolescent smokers. A Web-based survey data of the 15th Korea Youth Risk Behavior in 2019 has been used, and 7,026 adolescents who are currently smoking were selected as the subjects of the study. Data were analyzed using descriptive statistics and Logistic regression analysis with SPSS WIN 22.0 program. Logistic regression analysis showed that the following significant factors were related to attempts to quit smoking: cigarette pack warning picture recognition(in the last 30 days), ease of purchasing cigarettes(in the last 30 days), academic performance, secondhand smoke in public places(in the last seven days), grade, secondhand smoke in school(in the last seven days), secondhand smoke at home(in the last seven days). Based on these findings, it is thought that it is necessary to devise an easy way to recognize cigarette pack warning pictures for adolescent who have experienced smoking to quit smoking. It also shows the need to develop a smoking prevention program with families or friends of adolescent smoker and encourage them to participate together because the environmental factors of adolescent smoker affect smoking cessation.
\end{abstract}

Keywords: Smoking, Adolescent, Smoking Cessation, Somking Factor

요약: 본 연구는 우리나라 흡연 청소년의 금연에 미치는 영향요인을 확인하기 위해 시도되었다. 제15차(2019) 청소년건강행태온라인조사(KYRBWS) 자료를 활용하였으며 현재 흡연자인 청소년 7,026명을 연구 대상자로 선정하였다. 본 연구의 자료는 SPSS/WIN 22.0 프로그램을 이용하여 기술통계와 로지스틱 회귀분석을 이용하여 영향요인을 분석하였다. 흡연경험 청소년의 현재 금연에 가장 큰 영향을 미치는 요인으로는 담배갑경고 그림 인지(1.023)로 나타났으며, 그 외에도 담배구매 용이성이 높을수록, 가정내, 학교 실내, 공공장소 실내에서 간접흡연을 경험한 일수가 적을수록 금연시도가 높은 것으로 나타났다. 이러한 연구 결과들을 토대로 흡연을 경험한 청소년들의 금연을 위해서 담뱃갑 경고 그림을 쉽게 인지 할 수 있는 방법을 고안하는 것이 필요할 것으로 생각된다. 또한 흡연 청소년의 주변 환경 요인이 금연에 영향을 미치므로 흡연예방 프로그램을 진행할 때 흡연 청소년의

Received: March 06, 2021; $1^{\text {st }}$ Review Result: April 22, 2021; $2^{\text {nd }}$ Review Result: June 8, 2021 Accepted: July 31, 2021 
가족 혹은 친구들이 함께 참여할 수 있도록 유도할 필요성이 있음을 보여준다.

핵심어: 흡연, 청소년, 금연, 흡연요인

\section{1. 서론}

\section{1 연구의 필요성}

담배는 전 세계적으로 연간 약 60 만 명의 사망의 원인이 되는 건강을 위협하는 대표적인 발암물질이며, 흡연은 지난 수십 년 간 조기사망 및 폐암 등 각종 암의 이환을 비롯하여 여러 질병의 주요 원인으로 간주되고 있다[1]. 청소년기는 신체적 발달이 급격히 성장하는 시기로 유전자의 발암물질에 대한 감수성이 높아 흡연으로 인해 각종 질병이 발생할 위험이 매우 높으며[2], 세포, 조직 및 중추신경계에 니코틴, 일산화탄소, 타르 등이 영향을 주어 신체적으로 여러 위험을 높이며 불안, 우울과 같은 정신적 장애도 증가시킨다[3].

제 15 차(2019) 청소년건강행태조사 결과에 따르면 중·고등학생의 현재 흡연율은 $6.7 \%$ 로 2005 년에 비해 감소했으나 2016년을 기점으로 전체 여학생의 흡연율은 증가하고 있으며 남학생의 흡연을은 큰 차이가 없는 것으로 나타났다[4]. 한 달 내 액상형 전자담배를 사용한 중·고등학생은 $3.2 \%$ (남학생 $4.7 \%$, 여학생 $1.5 \%$ ), 궐련형 전자담배는 $2.6 \%$ (남학생 $4.0 \%$, 여학생 $1.2 \%$ )였다[4]. 금연 시도율은 흡연청소년의 $70 \%$ 정도의 높게 나왔으나 성공률은 저조한 것으로 나타났다[5].

최근 흡연 광고의 채널 및 형태가 다양하게 변화하여 유튜브 및 SNS 상의 흡연광고가 많아지고 있다. 청소년 매체이용 및 유해환경 실태조사에 따르면 청소년의 경우 주로 스마트폰을 활용하여 매체를 접하고 있으며, 스마트폰을 통한 SNS 이용 비율은 중학생의 $86.2 \%$, 고등학생의 $88.2 \%$ 이며[6] 하루 평균 스마트폰 이용 시간은 약 6 시간으로

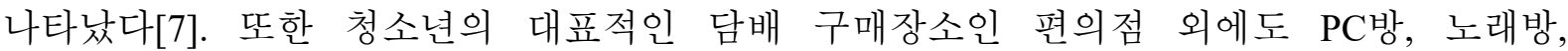
전자제품매장, 온라인 구매, 해외 직구 등 새로운 구매 방법들이 생겨 구매 경로의 변화가 생겨나고 있는 실정이다[6].

흡연경험 청소년에게 금연을 유도하는 일은 청소년의 신체적, 정신적, 사회적 건강을 위해서 매우 중요하므로 최근 청소년의 흡연 환경 변화에 맞춰 청소년 금연과 관련된 연구의 확대가 필요한 실정이다[8].

따라서 청소년기에 시작된 흡연은 중단이 어려워 대부분 성인이 될 때까지 지속되는 것으로 보고되고 있어 청소년시기에 흡연에 대한 호기심을 근절하는 것이 중요하므로[5][9], 성인 흡연으로 이어질 경우 앞으로의 질병 부담이 증가하게 되며 이는 막대한 사회·경제적 비용 발생으로 이어지게 된다[10].

그동안 청소년의 흡연 및 금연 관련 연구들이 많이 보고되고 있으나, 최근 흡연 광고의 변화와 청소년의 담배 구매경로의 변화, 전자담배 제품의 다양화 및 인식 변화 등 청소년의 변화된 흡연관련 특성을 고려한 다방면의 접근 방법이 요구되며 이를 토대로 청소년의 성공적인 금연을 돕기위해 차별화된 전략이 필요할 것이다.

이에 본 연구에서는 표본의 대표성이 높은 제15차(2019) 청소년건강행태온라인조사 자료를 이용하여 흡연 청소년의 금연에 미치는 영향을 파악함으로써 청소년의 흡연 
예방을 위한 간호중재 프로그램의 기초자료를 제공하고자 한다.

\section{2 연구 목적}

본 연구는 우리나라 흡연경험 청소년의 현재 금연에 미치는 영향을 확인하기 위함이다. 이를 위한 구체적 목적은 다음과 같다.

첫째, 흡연경험 청소년의 일반적 특성과 정서인지의 여부를 파악한다.

둘째, 금연 여부에 따른 흡연경험 청소년의 특성을 파악한다.

셋째, 흡연경험 청소년의 현재 금연과 관련이 있는 영향요인을 파악한다.

\section{2. 연구방법}

\section{1 연구설계}

본 연구는 우리나라 흡연 청소년의 금연에 미치는 영향요인을 확인하기 위해 제 15 차 (2019) 청소년건강행태온라인조사 자료를 이용하고자 원시자료 이용신청 후 승인을 받아 연구 목적에 맞게 분석한 이차자료 분석 연구이다.

\section{2 연구대상 및 자료수집 방법}

본 연구에 활용된 자료는 제 15 차(2019) 청소년건강행태조사 원시자료로 자료의 공개 및 관리규정에 의거하여 제공받았다[8]. 연구 모집단은 온라인 조사에 참여한 중학교 400 개교, 고등학교 400 개교 총 800 개교의 60,100 명( $95.3 \%$ 참여율)을 대상으로 하였으며 57,303 명 중 무응답자 234명을 제외한 57,069명이 조사에 참여하였다. 본 연구 대상자는 조사 참여자 중 최근 한 달 이내에 1 일 이상 담배를 피운 경험이 있는 현재 흡연자인 청소년 7,026명을 최종 연구 대상자로 선정하였다.

\section{3 연구도구}

\subsection{1 흡연경험 청소년}

본 연구에서 조사 당시‘최근 30 일 동안 일반담배(궐련)를 한 개비라도 피운 날은 며칠 입니까?’라는 설문 문항에 최근 1달 이내 1 일 이상 흡연하였다고 답변한 경우를 흡연경 험 청소년으로 정의하였다.

\subsection{2 금연학생}

조사 대상자가 “최근 30 일 동안, 일반담배(궐련)를 한 개비라도 피운 날은 며칠 입니까?”라는 설문 문항에 “최근 30 일 동안 없다’라고 응답한 경우를 금연학생으로 정의하였다.

\subsection{3 일반적 특성}

대상자의 일반적 특성은 성별, 학년, 성적 및 경제적 상태로 구성하였다. 


\subsection{4 정서인지 특성}

대상자의 정서인지 특성은 주관적 건강인지, 주관적 체형인지 및 평상시 스트레스 인지로 구성하였다.

\section{4 자료분석}

본 연구의 자료는 SPSS/WIN 22.0 프로그램을 이용하여 다음과 같이 분석하였다.

1) 연구대상자의 일반적 특성과 정서인지 특성은 빈도와 백분율, 평균과 표준편차로 분석하였다.

2) 현재 금연 여부에 따른 흡연경험 청소년의 특성 차이는 t-test, one way ANOVA, 사후 검정은 Scheffe test를 실시하였다.

3) 현재 금연에 미치는 영향요인을 파악하기 위해 로지스틱 회귀분석(Logistic regression analysis)을 이용하여 분석하였다.

\section{3. 결과}

\section{1 흡연청소년의 일반적 특성}

본 연구 대상자는 현재 흡연자인 청소년 7,026 명이며, 성별은 남학생과 여학생이 각각 4,971명(70.8\%), 2,055명(29.2\%)으로 남학생이 2배이상 많았고, 중학생은 2,081명 $(29.5 \%)$, 고등학생은 4,945 명 $(70.5 \%)$ 으로 이또한 2 배 이상 많았다.

학교 성적은 ‘상’ 678 명(9.6\%), ‘중-상’ 1,211 명(17.2\%), ‘중' 1,801명(25.6\%), ‘중-하’ 1,931명 (27.5\%), ‘하’ 1,405 명(20.0\%)로 ‘중-하’가 가장 많았고, 경제적 상태는 ‘중-상' 1,702 명 $(45.2 \%)$, ‘상’ 802 명(24.2\%), ‘중’ 3,177명(25.6\%), ‘중-하’ 1,012명(14.4\%), ‘하’ 333 명(4.7\%)순이었다.

정서인지 특성에서 주관적 건강 인지요인에서는 '건강한 편' 2,734 명(35.9\%), '매우 건강한 편' 2,093 명(29.8\%), ‘보통' 1,515 명(21.6명)으로 흡연 청소년 중 $87.3 \%$ 는 본인이 보통이상으로 건강하다고 느끼고 있었다.

주관적 체형인지요인에서는 '보통' 2,389명(34.0\%), ‘약간 살이 찐 편' 2,227명(31.7\%), ‘약간 마른 편' 1,536 명(21.9명)으로 나타났으며, 평상시 스트레스 인지요인에서는 '조금 느낌' 2,552 명(36.3\%), ‘많이 느낌' 2,061 명(29.3\%), ‘대단히 많이 느낌' 1,241 명 $(17,7 \%)$ 으로 흡연 청소년 중 $83.3 \%$ 가 평상시 스트레스를 느끼는 것으로 나타났다[Table 1].

[표 1] 흡연청소년의 일반적 특성 $(\mathrm{N}=7,026)$

[Table 1] General Characterisitcs of Adolescent Smokers(N=7,026)

\begin{tabular}{|c|c|c|c|c|}
\hline \multirow{2}{*}{ Variables } & Categories & Sub-categories & $\mathrm{n}(\%)$ & Mean \pm sd \\
\hline \multirow{2}{*}{ Gender } & Male & & $4971(70.8)$ & \\
\cline { 2 - 5 } & Female & & $2055(29.2)$ & \\
\hline \multirow{2}{*}{ Grade } & Middle 1st(1) & & $249(3.5)$ & \multirow{2}{*}{$4.33 \pm 1.45$} \\
\cline { 2 - 5 } & Middle 2nd & & $677(9.6)$ & \\
\hline
\end{tabular}




\begin{tabular}{|c|c|c|c|c|}
\hline & Middle 3rd & & $1155(16.4)$ & \\
\hline & High 1st & & $1335(19.0)$ & \\
\hline & High 2nd & & $1659(23.6)$ & \\
\hline & High $3 \mathrm{rd}(6)$ & & $1955(27.8)$ & \\
\hline \multirow{5}{*}{$\begin{array}{c}\text { Academic } \\
\text { Performance }\end{array}$} & High(1) & & $678(9.6)$ & \multirow{5}{*}{$3.31 \pm 1.24$} \\
\hline & Middle-High & & $1211(17.2)$ & \\
\hline & Middle & & $1801(25.6)$ & \\
\hline & Middle-Low & & $1931(27.5)$ & \\
\hline & $\operatorname{Low}(5)$ & & $1405(20.0)$ & \\
\hline \multirow{5}{*}{$\begin{array}{l}\text { Economic } \\
\text { Status }\end{array}$} & High(1) & & $802(11.4)$ & \multirow{5}{*}{$2.77 \pm 0.99$} \\
\hline & Middle-High & & $1702(24.2)$ & \\
\hline & Middle & & $3177(45.2)$ & \\
\hline & Middle-Low & & 1012(14.4) & \\
\hline & $\operatorname{Low}(5)$ & & $333(4.7)$ & \\
\hline \multirow{15}{*}{$\begin{array}{l}\text { Emotional } \\
\text { Cognition }\end{array}$} & \multirow{5}{*}{$\begin{array}{c}\text { Perceived } \\
\text { Health Status }\end{array}$} & Very Healthy(1) & 2093(29.8) & \multirow{5}{*}{$2.12 \pm 0.97$} \\
\hline & & Healthy & $2734(35.9)$ & \\
\hline & & Normal & $1517(21.6)$ & \\
\hline & & Unhealthy & $599(8.5)$ & \\
\hline & & Very Unhealthy(5) & $83(1.2)$ & \\
\hline & \multirow{5}{*}{$\begin{array}{l}\text { Perceived } \\
\text { Body Shape }\end{array}$} & Very Slim(1) & $328(4.7)$ & \multirow{5}{*}{$3.16 \pm 1.00$} \\
\hline & & Slim & $1536(21.9)$ & \\
\hline & & Normal & $2389(34.0)$ & \\
\hline & & Fatty & $2227(31.7)$ & \\
\hline & & Very Fatty(5) & $546(7.8)$ & \\
\hline & \multirow{5}{*}{$\begin{array}{l}\text { Perceived } \\
\text { Stress }\end{array}$} & Very High (1) & $1241(17.7)$ & \multirow{5}{*}{$2.55 \pm 1.04$} \\
\hline & & High & $2061(29.3)$ & \\
\hline & & Moderate & $2552(36.3)$ & \\
\hline & & low & $932(13.3)$ & \\
\hline & & None(5) & $240(3.4)$ & \\
\hline
\end{tabular}




\section{2 금연 여부에 따른 흡연경험 청소년의 차이}

금연 여부에 따른 흡연경험 청소년의 특성을 살펴보면, 첫 흡연 연령이 비흡연군과 흡연군에서 중 1 이상으로 유의미한 차이가 없었고 $(\mathrm{p}=.084)$, 지난 7일 동안 담배 구입의 어려움은 두 군에서 유의미한 차이가 있었다( $\mathrm{p}<.001)$.

최근 7일 동안의 가정내 간접흡연 경험은 두군 사이에 유의미한 차이가 있었다(p<.001). 최근 7일동안 학교실내 간접흡연 경험도 두군 사이에 유의미한 차이가 있었으며 $(\mathrm{p}<.001)$, 학업성적( $\mathrm{p}<.001)$, 학년(p<.001), 최근 30일 동안 담뱃갑 경고 그림 인지 $(\mathrm{p}<.001)$, 인지하는 건강상태 $(\mathrm{p}=.031)$, 인지하는 스트레스 정도 $(\mathrm{p}=.001)$ 에서도 두 군 사이에 유의미한 차이가 있었다.

그러나, 경제적 상태 $(\mathrm{p}=.976)$, 성별 $(\mathrm{p}=.076)$ 및 인지하는 체형 $(\mathrm{p}=.057)$ 에서는 유의미한 차이가 없었다[Table 2].

[표 2] 금연 여부에 따른 흡연청소년의 일반적 특성 $(\mathrm{N}=7,026)$

[Table 2] General Characterisitcs of Adolescent Smokers according to Smoking Status $(\mathrm{N}=7,026)$

\begin{tabular}{|c|c|c|c|c|c|}
\hline Variables & Categories & $\begin{array}{l}\text { Non-smoking } \\
\qquad(\mathrm{n}=3,801)\end{array}$ & $\begin{array}{l}\text { Smoking } \\
(n=3,225)\end{array}$ & $\chi^{2}$ or $\mathrm{F}$ & $\mathrm{p}$ \\
\hline \multirow{13}{*}{$\begin{array}{c}\text { Start Time of } \\
\text { Experience of Smoking }\end{array}$} & Preschool(1) & \multirow{13}{*}{$8.54 \pm 2.36$} & \multirow{13}{*}{$8.63 \pm 2.23$} & \multirow{13}{*}{-1.73} & \multirow{13}{*}{0.084} \\
\hline & Elementary 1st & & & & \\
\hline & Elementary 2nd & & & & \\
\hline & Elementary 3rd & & & & \\
\hline & Elementary 4th & & & & \\
\hline & Elementary 5th & & & & \\
\hline & Elementary 6th & & & & \\
\hline & Middle 1st & & & & \\
\hline & Middle 2nd & & & & \\
\hline & Middle 3rd & & & & \\
\hline & High 1st & & & & \\
\hline & High 2nd & & & & \\
\hline & High 3rd(13) & & & & \\
\hline \multirow{3}{*}{$\begin{array}{c}\text { Ease of Purchasing } \\
\text { Cigarettes } \\
\text { (in the last } 7 \text { days) }\end{array}$} & Not Trying(1) & \multirow{3}{*}{$2.91 \pm 1.663$} & \multirow{3}{*}{$1.31 \pm 0.922$} & \multirow{3}{*}{48.50} & \multirow{3}{*}{$<.001$} \\
\hline & Impossible & & & & \\
\hline & Buy if Try & & & & \\
\hline
\end{tabular}




\begin{tabular}{|c|c|c|c|c|c|}
\hline & Buy with a little Effort & & & & \\
\hline & Buy without Effort(5) & & & & \\
\hline \multirow{8}{*}{$\begin{array}{l}\text { Secondhand Smoke } \\
\text { at Home } \\
\text { (in the last } 7 \text { days) }\end{array}$} & None during the last 7 days(1) & \multirow{8}{*}{$2.97 \pm 2.728$} & \multirow{8}{*}{$2.39 \pm 2.379$} & \multirow{8}{*}{9.43} & \multirow{8}{*}{$<.001$} \\
\hline & 1days a week & & & & \\
\hline & 2days a week & & & & \\
\hline & 3days a week & & & & \\
\hline & 4days a week & & & & \\
\hline & 5days a week & & & & \\
\hline & 6days a week & & & & \\
\hline & Every day(8) & & & & \\
\hline \multirow{8}{*}{$\begin{array}{l}\text { Secondhand Smoking } \\
\text { in schools } \\
\text { (in the last } 7 \text { days) }\end{array}$} & None during the last 7 days(1) & \multirow{8}{*}{$2.45 \pm 2.424$} & \multirow{8}{*}{$1.80 \pm 1.810$} & \multirow{8}{*}{12.71} & \multirow{8}{*}{$<.001$} \\
\hline & 1days a week & & & & \\
\hline & 2days a week & & & & \\
\hline & 3days a week & & & & \\
\hline & 4days a week & & & & \\
\hline & 5days a week & & & & \\
\hline & 6days a week & & & & \\
\hline & Every day8) & & & & \\
\hline \multirow{8}{*}{$\begin{array}{l}\text { Secondhand Smoking } \\
\text { inside Public Place } \\
\text { (in the last } 7 \text { days) }\end{array}$} & None during the last 7 days(1) & \multirow{8}{*}{$3.62 \pm 2.603$} & \multirow{8}{*}{$2.69 \pm 2.123$} & \multirow{8}{*}{16.26} & \multirow{8}{*}{$<.001$} \\
\hline & 1days a week & & & & \\
\hline & 2days a week & & & & \\
\hline & 3days a week & & & & \\
\hline & 4days a week & & & & \\
\hline & 5days a week & & & & \\
\hline & 6days a week & & & & \\
\hline & Every day8) & & & & \\
\hline Academic Performance & & $3.41 \pm 1.265$ & $3.19 \pm 1.199$ & 7.42 & $<.001$ \\
\hline Economic Status & & $2.77 \pm 1.019$ & $2.77 \pm 0.954$ & -0.03 & 0.976 \\
\hline
\end{tabular}




\begin{tabular}{|c|r|c|c|c|c|}
\hline Grade & & $4.47 \pm 1.393$ & $4.17 \pm 1.499$ & 8.80 & $<.001$ \\
\hline \multirow{2}{*}{$\begin{array}{c}\text { Cigarette Pack Warning } \\
\text { Picture recognition } \\
\text { (in the last 30 days) }\end{array}$} & Yes(1) & $1.90 \pm 0.295$ & $1.71 \pm 0.454$ & 461.930 & $<.001$ \\
\cline { 2 - 6 } & No(2) & $1.28 \pm 0.451$ & $1.30 \pm 0.460$ & 3.15 & 0.076 \\
\hline \multirow{2}{*}{ Gender } & Perceived Health Status & $2.15 \pm 0.996$ & $2.10 \pm 0.943$ & 2.16 & 0.031 \\
\cline { 2 - 6 } Emotional \\
Cognition & Perceived Body Shape & $3.14 \pm 1.010$ & $3.19 \pm 0.996$ & -1.90 & 0.057 \\
\cline { 2 - 6 } & Perceived Stress & $2.52 \pm 1.058$ & $2.60 \pm 1.005$ & -3.25 & 0.001 \\
\hline
\end{tabular}

\section{3 흡연경험 청소년의 현재 금연 영향요인}

차이분석을 통해 유의미한 차이를 나타낸 담배구매용이성, 가정내 간접흡연, 학교실내 간접흡연, 공공장소실내 간접흡연, 학업성적, 학년, 담배갑 경고 그림인지 중에서 흡연 청소년의 금연에 미치는 영향요인이 무엇인지를 검정하기 위해 로지스틱 회귀분석을 실시하였다.

그 결과, 회귀모형은 유의한 것으로 나타났으며 $(\chi 2=2336.632, \mathrm{p}<.001)$, 모형의 설명력을 나타내는 Nagelkerke의 결정계수(R2)도 $38.0 \%$ 의 설명력을 보여주고 있다. 흡연경험 청소년의 현재 금연에 가장 큰 영향을 미치는 요인으로는 담배갑경고 그림 인지(1.023)로 나타났으며, 그 외에도 담배구매 용이성이 높을수록, 가정내, 학교실내, 공공장소 실내에서 간접흡연을 경험일수가 적을수록 금연시도가 높은 것으로 나타났다 [Table3].

[표 3] 현재 금연 여부에 따른 흡연청소년의 일반적 특성 $(\mathrm{N}=7,026)$

[Table 3] General Characterisitcs of Adolescent Smokers according to Smoking Status(N=7,026)

\begin{tabular}{|c|c|c|c|c|c|}
\hline Variables & B & SE & Wald & OR \\
\hline $\begin{array}{c}\text { Ease of Purchasing Cigarettes } \\
\text { (in the last 30 days) }\end{array}$ & -0.796 & 0.024 & 1070.993 & $<.001$ & 0.451 \\
\hline $\begin{array}{c}\text { Secondhand Smoke at Home } \\
\text { (in the last seven days) }\end{array}$ & -0.033 & 0.012 & 7.559 & 0.006 & 0.968 \\
\hline $\begin{array}{c}\text { Secondhand Smoke in School } \\
\text { (in the last seven days) }\end{array}$ & -0.043 & 0.016 & 7.640 & 0.006 & 0.958 \\
\hline $\begin{array}{c}\text { Secondhand Smoke in Public Places } \\
\text { (in the last seven days) }\end{array}$ & -0.050 & 0.014 & 12.959 & $<.001$ & 0.951 \\
\hline Academic Performance & -0.118 & 0.024 & 24.905 & $<.001$ & 0.889 \\
\hline Grade & -0.046 & 0.020 & 5.319 & 0.021 & 0.955 \\
\hline
\end{tabular}




\begin{tabular}{|c|c|c|c|c|c|}
\hline $\begin{array}{c}\text { Cigarette Pack Warning Picture recognition } \\
\text { (in the last 30 days) }\end{array}$ & 1.023 & 0.078 & 173.974 & $<.001$ & 2.783 \\
\hline (Constant) & 2.090 & 0.171 & 148.593 & $<.001$ & 8.082 \\
\hline
\end{tabular}

\section{3. 결론}

본 연구는 표본의 대표성이 높은 제 15 차(2019) 청소년건강행태 온라인조사 자료를 이용하여 우리나라 흡연 청소년의 금연에 영향을 미치는 관련요인을 조사하여 청소년 금연 프로그램 개발과 금연 정책의 기초자료를 제공하고자 하였다.

본 연구에서는 가정, 학교 및 공공장소 실내에서 간접흡연에 덜 노출될수록 금연에 영향을 미치는 것으로 나타났으며 흡연경험 청소년의 담뱃갑 경고 그림 인지 시 흡연 청소년의 금연 시도가 높은 것으로 나타났다. 이러한 연구 결과들을 토대로 흡연 청소년의 주변 환경요인이 금연에 영향을 미치므로 흡연 청소년의 가족 혹은 친구들과 동반된 금연 교육이나 중재 프로그램을 개발하여 함께 참여하도록 유도할 필요성이 있음을 보여준다.

흡연을 경험한 청소년들의 금연을 위해서 담뱃갑 경고 그림을 쉽게 인지 할 수 있는 방법을 고안하는 것이 필요할 것으로 생각된다. 또한 청소년들이 쉽게 접근할 수 있는 TV나 인터넷 매체를 통해 금연관련 캠페인이 지속적으로 이루어지는 것이 금연 성공에 효과적일 것이라고 사료된다.

\section{References}

[1] World Health Organization, WHO Report on the Global Tobaco Epidemic: Warning about the dangers of tobacco, IDEAS Working Paper Series from RePEc, (2011). https://apps.who.int/iris/handle/10665/44616

[2] E. S. Lim, J. H. Yoo, An Analysis of the Factors Affecting Smoking Adolescents, Journal of Korean Academy of Community Health Nursing, (2006), Vol.17, No.2, pp.253-262.

[3] Y. S. Byeon, H. S. Lee, Relation of the Blood Pressure, Lipids and Body Mass Index by Smoking Status Among Adolescents, Journal of Korean Academy of Nursing, (2007), Vol.37, No.6, pp.1020-1026.

[4] 15th Youth Health Behavior Survey Results, Centers for Disease Control and Prevention, (2019), https://www.kdca.go.kr/index.es?sid=a2

[5] https://www.khealth.or.kr/kps, Nov 11 (2020)

[6] Ministry of Gender Equality and Family, The Suvey on Adolescents' Media Use and Hazardous Environment in 2018, (2019), http://www.mogef.go.kr/kor/skin/doc.html?fn=c25def92798c4deabed5f113a6bd9e57.pdf\&rs=/rsfiles/202203/

[7] Tweens' and Teens' Media Use in Korea 2019, Korea Press Foundation,(2019), https://www.kpf.or.kr/front/user/main.do

[8] J. Y. Park, Factors affecting Attempts to Quit Smoking in Korean Adolescents, The Journal of the Korean Society of School Health, (2016), Vol.29, No3, pp.277-285.

[9] D. M. Fergusson, H. L. John, Transitions to cigarette smoking during adolescence, Addictive Behaviors, (1995), Vol.20, No.5, pp.627-642. 
[10] K. O. Chang, E. K. Byun, N. Y. Lee, S. Y. Choi, The Effects of Knowledge about the Harmfulness of Smoking and Attitude Toward Smoking Temptation for Middle School Students, Journal of Korean Academy of Community Health Nursing, (2006), Vol.17, No.2, pp.253-262. 